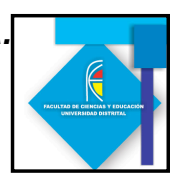

\title{
IMPLEMENTACIÓN DE LA SUPERCONDUCTIVIDAD EN LOS ESTADOS DE LA MATERIA PARA EDUCACIÓN MEDIA
}

\section{IMPLEMENTATION OF SUPERCONDUCTIVITY IN STATES OF MATTER IN SECONDARY EDUCATION}

\author{
Judy Carolina Anacona Beltrán \\ Yessica Acosta Urian ${ }^{1}$
}

\begin{abstract}
Resumen
Lo que se quiere trabajar en esta propuesta es la introducción de la superconductividad, como un estado de la materia, en el programa de educación media (grados 10-11); de forma práctica, didáctica y activa de docente a estudiante y viceversa; mediante la aplicación de estrategias pedagógicas que faciliten la comprensión del mismo, promoviendo una cultura científica que permita evidenciar un puente entre la física y la vida real para que esta no sea ajena a ellos; llegando al fin principal de entender sus múltiples aplicaciones (tren MagLev) y los diferentes campos de acción que puede llegar a tener (superconductores a temperatura ambiente). Por otra parte se pretende posibilitar en la escuela la comprensión de las características de la materia microscópicamente en el estado de superconductividad, ya que para la aproximación del mismo es necesario este tipo de explicación; concluyendo con ideas más profundas, que una relación con la facilidad de flujo de corriente eléctrica en algunos materiales a bajas temperaturas y desaparición de la resistividad eléctrica, destacando que representó el desarrollo tecnológico más importante del siglo XX, por esto y más se desea transmitir esta idea a cada estudiante.
\end{abstract}

Palabras Clave: Temperatura, resistividad, superconductividad, estrategias pedagógicas, estado, calor, electrón, fonón.

\begin{abstract}
${ }^{l}$ Estudiantes de Licenciatura en Física, Universidad Pedagógica Nacional.

b.ab.yjudy@live.com, hikaru_yessi@hotmail.com
\end{abstract}

What it wants to work in this proposal is the introduction of the superconductivity, as a matter state, in the middle school program (grades 10-11), in a practical, didactic and active way, from teacher to student and likewise inversely; through the application of pedagogical strategies that facilitate the understanding of it, promoting a scientific culture that allows a connection between physics and true life, that is not unknowledge to them; getting to a main goal of understand their multiple applications (MagLev Train) and the different action fields that it could have (superconductors in a ambient temperature). On 


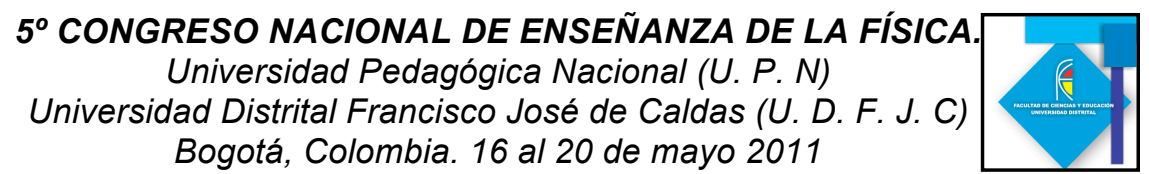

the other hand it pretends to enable in the school the comprehension of the microscopically matter characteristic in the superconductivity state, because is necessary the approximation on this explanation for how is it; concluding with deeper ideas, than a relation of the flow facility of electric current in some materials in low temperatures and disappearance of the electric resistivity, taking into account that represented it represents the technological development more important of the twentieth century, for those and more reasons it is necessary to transmit this idea to each student.

Keywords: Temperature, resistivity, superconductivity, pedagogical strategy, state, electron, phonon.

\section{Introducción}

Desde la visión que tenemos como futuros maestros de física; vemos la necesidad de relacionar nuestra disciplina académica con la aplicación de la misma y de generar conocimientos que incrementen la capacidad de acción y desarrollen una actitud de investigador en el estudiante.

En la física así como en algunas otras ciencias los estudiantes generalmente presentan falencias ya que es vista por ellos como un estudio fuera de su alcance o no representa aporte alguno para su desarrollo. Sin embargo frente a esto es necesario un trabajo docente orientador; que genere puentes entre las ciencias y la vida real, que dé a conocer además de lo ya estipulado, los avances, las innovaciones y sus campos de desarrollo para conseguir la atención y reconocimiento de la misma por parte del estudiante.

Nuestro objetivo principal es aproximar al estudiante el concepto de superconductividad desde la presentación del tema, el experimento y sus aplicaciones. La estrategia didáctica ha sido propuesta; para un grupo de estudiantes de grado (10-11), con el fin de superar las falencias ya mencionadas, con el uso de analogías, cuentos o relatos e imágenes que logren propiciar; la comprensión cualitativa de la superconductividad de una manera didáctica.

\section{Proceso de Enseñanza del Estado Superconductor}

\section{Temáticas desarrolladas}

Es importante destacar que se abordo el estado superconductor de la materia, en el siguiente orden:

Estados de la materia, Temperatura, calor, corriente, resistencia, campo magnético, conductores perfectos, superconductores, clases de electrones, superelectrones, clases de superconductores, esquema protón-Fonón y aplicaciones.

\section{Uso de Estrategias Didácticas en la Enseñanza de la Superconductividad}

"El factor más importante que influye en el aprendizaje es lo que el alumno ya sabe. Averígüese esto y enséñese consecuentemente" (Ausubel) 


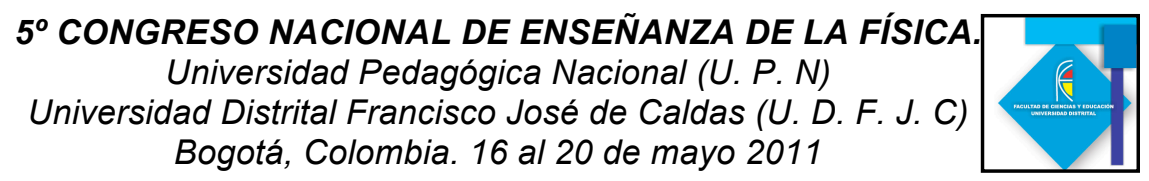

Es importante destacar que la estrategia de enseñanza que implementamos tiene como base inicial las nociones previas de los estudiantes; con base a esto partimos de las ideas ya concebidas para hacer un buen manejo de estas y lograr un almacenamiento en la memoria a largo plazo, lo cual creemos más pertinente que una construcción total que requiere un mayor esfuerzo para la memoria.

Partiendo de lo anterior lo primero que se hizo fue conocer las nociones que tenían los estudiantes acerca de los estados de la materia, superconductividad y la corriente eléctrica, por medio de encuestas y preguntas en donde evidenciamos las ideas previas que conocían del tema. Algunas de las respuestas de los estudiantes se presentan a continuación.

- "Los estados de la materia son diferentes formas en que pueden estar las moléculas del material para formar diferentes configuraciones como lo son liquido, solido y gaseoso"

- "Para mí la corriente eléctrica es el flujo de energía que existe en los cables que hacen que funcionen los aparatos eléctricos, como los electrodomésticos"

- "Yo creo que como su nombre lo indica un superconductor es un conductor que permiten que pase corriente eléctrica a través de un circuito eléctrico"

Como lo evidenciamos anteriormente cuando preguntamos el significado de superconductividad, corriente eléctrica y estados de la materia entre ellos no se observa ninguna relación, pero si tienen la noción de lo que sucede cuando existe corriente o cuando la materia cambia su estado; entonces de ahí partimos para precisar, entender y relacionar sus conceptos a través de:

1. cuentos 0 relatos aportando consigo otros aspectos importantes como temperatura comportamiento del electrón y fotón. Un fragmento de un cuento es:

"Un emperador se encontraba llorando por algo que le habían enseñado en su más tierna edad y además fácil de verificar, siempre había creído que la materia existía bajo tres formas: solida, liquida y gaseosa. Después, le habían hablado de otras formas que nunca le habían sido reveladas. El lograba siempre hacer entrar las cosas extrañas que le presentaban en alguna de las tres categorías. Los sólidos eran duros, los líquidos se deslizaban por sus preciosas alfombras cuando volcaba los recipientes, en cuanto a los gases, llenaban invariablemente el volumen en el que se lo soltaba"[2].

2. analogías como:

"Un columpio por muy fuerte que se empuje siempre terminara deteniéndose. La energía suministrada por nuestros brazos se perderá por rozamiento del columpio con el aire y por la fricción de los engranajes o la cadena con la estructura que soporta el columpio. Ahora imaginemos un columpio que nunca parase. Una vez empujado, continuaría oscilando siempre a la misma velocidad, eternamente. Lo mismo sucede con un conductor cuando la corriente fluye termina por dispersarse a causa de la resistencia eléctrica. Sin embargo, en un superconductor la energía no 


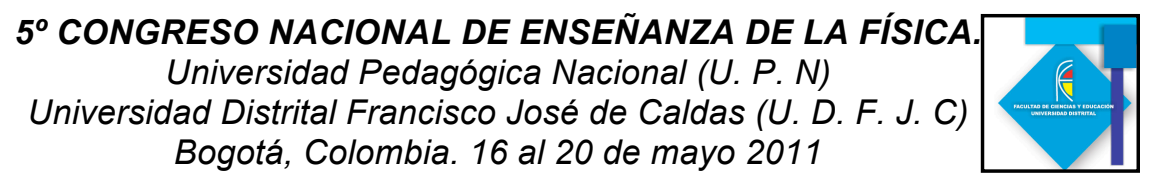

se pierde, sino que la corriente podría fluir eternamente, puesto que no hay nada que se oponga a ello"[3].

"Imagine que va caminado por un sendero que presenta obstáculos a su paso: grandes pedruscos, agujeros, etc.: le cuesta trabajo avanzar pues cae al tropezar con los diversos obstáculos. Existe una resistencia a su avance pues resulta lento y le cuesta mucha energía. Ahora suponga que no camina solo, sino en parejas. Así, cuando un miembro de la pareja caiga en un bache, el otro lo ayudara a salir y podrá reanudar su marcha. Así brazo con brazo, será más fácil sortear los obstáculos del camino. Ahora suponga que en lugar de avanzar en parejas lo hace en tercetos, en cuartetos, etc. Sera aun más difícil que el terceto, el cuarteto, etc. sea detenido en su camino, porque tendrían que caer todos los elementos del conjunto simultáneamente. Como consecuencia, al trasladarse brazo con brazo los más que se puedan, disminuirá la resistencia a nuestro avance" (Magaña, 1997)

3. imágenes que expresen el comportamiento superconductor de la materia como:

a) $\bar{B}=0$
$T>T_{C}$

b)

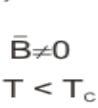<smiles>c1ccccc1</smiles>

c) $\overline{\mathrm{B}}=0$
$\mathrm{~T}<\mathrm{T}_{\mathrm{C}}$

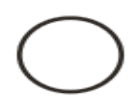

d)

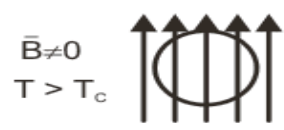

e)

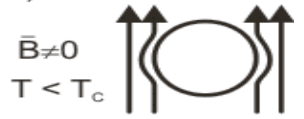

f)

$\overline{\mathrm{B}}=0$

$\mathrm{T}<\mathrm{T}_{\mathrm{C}}$
Figura 1. Comportamiento de un superconductor en un campo magnético, a diferentes temperaturas [1].

4. aplicaciones

La superconductividad como muchos de los descubrimientos científicos en la historia, inicialmente permaneció como tal sin ningún aporte práctico a la sociedad. Sin embargo en el caso de los superconductores gracias al trabajo de muchos científicos se desarrollo hasta convertirse en una de las múltiples aplicaciones de la física teórica como lo afirma el autor Jonathan Mayo:"Después de 75 años de relativa oscuridad, la física de superconductores se está aplicando ahora en muchos campos diferentes: medicina, ciencias teóricas y experimentales, defensa, transportes, producción de electricidad, electrónica y muchos otros" [3].

Gracias a las múltiples aplicaciones que se han desarrollado, como lo menciona el autor, es posible hoy considerar la superconductividad como uno de los avances tecnológicos que prometen revolucionar el futuro de la humanidad (los países industrializados ven una oportunidad en la superconductividad para la nueva carrera tecnológica). 


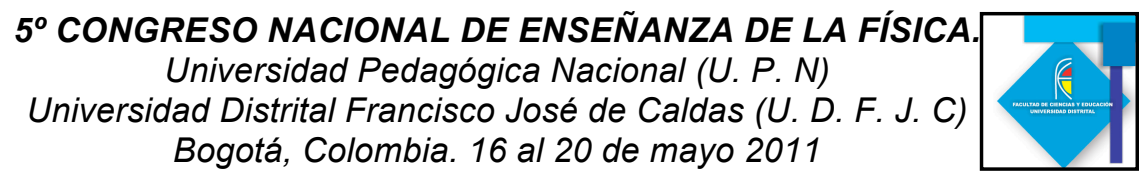

5. Experimento

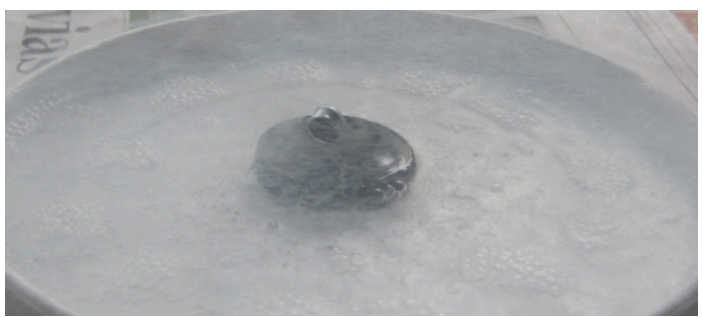

Figura 2. Experimento (levitación magnética)

Hay que resaltar que la aplicación del experimento (efecto Meissner) logra involucrar de manera más activa al estudiante.

\section{Resultados}

Las actividades realizadas contribuyeron al análisis y compresión de conceptos físicos, como superconductividad, corriente eléctrica, estado, temperatura, entre otros; evidenciaron que por medio de aplicaciones los estudiantes mostraron la utilidad de la física en la vida real; crearon una mejor compresión y disposición por medio del experimento lo cual genero curiosidad por aspectos disciplinares de nuestra área; permitieron que los estudiantes reconocieran los campos de acción del estado superconductor de la materia.

\section{Conclusiones}

La enseñanza de nuestra área disciplinar necesita de temas con características novedosas que puedan ser implementadas en el aula para incrementar la capacidad de acción y desarrollar una actitud de investigación en el individuo. Así como para que el estudiante pueda construir y modificar conocimientos en vez de memorizarlos y repetirlos. Al entender el estado, sus propiedades y sus diferentes campos de acción que pueden llegar a trascender nuestro entorno (trenes rápidos de levitación magnética, producción de campos magnéticos de una intensidad inigualable y transportación de corriente eléctrica sin pérdidas) llevamos al estudiante a involucrarse con la física.

\section{Agradecimientos}

Esta propuesta fue apoyada por la profesora Isabel Garzón de la Universidad Pedagógica Nacional, a la profesora Rusby Malagón y el profesor Diego Julián Rodríguez de la línea de investigación y construcción de conocimiento desde la perspectiva didáctica, ya que nos incentivaron para realizar la investigación dirigida a la superconductividad, al profesor David Landinez Téllez por facilitarnos el material cerámico para la realización del experimento.

\section{Referencias}

Magaña Solís, L. (1997). Los superconductores. México D.F.: Fondo de Cultura económica. 


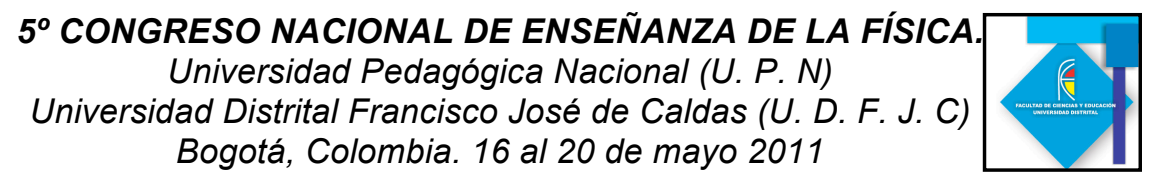

Sven Ortoli, J. (1990). Historia y leyendas de la superconductividad. Barcelona, España: Editorial Edisa.

Mayo, J. y Miranda Pantoja, J. (1991). Superconductividad: el umbral de una nueva tecnología. Madrid, España: McGraw-Hill. 